\title{
AOR
}

Selected Papers of \#AolR2020:

The $21^{\text {st }}$ Annual Conference of the

Association of Internet Researchers

Virtual Event / 27-31 October 2020

\section{PANEL SUBMISSION: MEDIATING MENTAL ILLNESS: DIGITAL LIFEWORLDS, PLATFORMS AND ALGORITHMS}

\author{
Evelyn Wan \\ Institute for Cultural Inquiry, Utrecht University \\ Jacinthe Flore \\ School of Global, Urban and Social Studies, RMIT University \\ Anthony McCosker \\ Social Innovation Research Institute, Swinburne University of Technology \\ Peter Kamstra \\ Swinburne University of Technology \\ Jane Farmer \\ Swinburne University of Technology \\ Natalie Hendry \\ School of Media and Communication, RMIT University
}

How is "mental illness" and mental ill-health conceptualised, designed or experienced by and through digital life? What "is" data related to mental ill-health? This panel explores how digital technologies and media have transformed rhetoric, discourses and practices related to mental ill-health. We bring together different methodological and theoretical contributions towards an interdisciplinary study of mental illness and digital life.

A considerable amount of data related to emotional states and experiences is currently being collected on and by individuals today. Sometimes, collection is obvious, as in the biometric readings displayed on apps used for fitness and mood tracking, posts shared on online forums to convey social isolation, or the transcripts we generate talking to bots designed to assist us with mental-health related queries. Other times, collection is harder to determine, as on social media platforms where users receive pop-up

Suggested Citation (APA): Evelyn Wan, E., Flore, J., McCosker, A., Hendry, N.A., Kamstra, P. \& Farmer, J. (2020, October 28-31). Mediating mental illness: Lifewords, platforms, and algorithms. Panel presented at AolR 2020: The 201 ${ }^{\text {th }}$ Annual Conference of the Association of Internet Researchers. Dublin, Ireland:

AolR. Retrieved from http://spir.aoir.org. 
"intervention" messages inquiring about their state of mind, or directing them to counselling services.

For their part, corporations have engaged with this data to categorise, treat and predict mental illness, or shape possibilities for users' experiences of emotional distress, trauma and mental ill-health. Machine learning is purportedly well-suited to "dementalise" psychiatry (Castel 2000, in Ross 2006); that is, use descriptive language to diagnose, and ultimately predict mental illness. Today it is used to "coach" users to psychological recovery in support apps to alleviate distress and isolation (e.g. Fuller et al. 2020, Parshley 2020). Further, corporations market machine learning in hospital "smart rooms" as a technology with a dual function: it provides a cost-effective way to monitor patients, and using aggregated data, it generates "optimal treatment paths" for the hospital to adopt in the future.

This collection of papers considers the social and cultural contexts of mental ill-health and digital technology. We hope to expand discussions at previous AOIR conferences beyond the impact of social media or digital technology on individuals' mental health; the impacts of public health communication about mental health; the clinical outcomes of digital treatment or e-therapy; or mediated representations of mental health. We ask what does mental ill-health related data produce, materially, culturally and politically? What happens when this data is absent or made visible or invisible? How is "mental illness," "mental ill-health" or "emotional distress" recognised, enacted upon, discursively produced and practiced through digital platforms and user interactions? How do 'truth claims' made using mental-health data map to material contexts and histories of mental illness? How do they intersect with the cultural politics of the day and location?

Our first two papers analyse mental health data, specifically chatbots and ingestible sensors that are used for diagnosis, monitoring, and treatment of mental illness in their entanglements with private companies, state policy, and university lab experimentations. Our first paper frames the emerging field of computational psychiatry as a biopolitical form of governance of mental illness through algorithmic and digital means, and analyses the logic of control through the example of a cognitive-behavioural therapy chatbot for depression and anxiety. The second paper turns to the body as a site of intervention for the treatment of psychiatric diagnoses. Drawing on theories of new materialism, this paper explores how we can think through the assemblages of digital technology, embodiment and moods associated with mental illness.

We discuss the experience of mental ill-health and related data cultures as they intersect with the social and cultural politics, as well as the historical and material contexts, of mental illness. Understanding online forums as potentially "enabling places," the third paper discusses the relationships between space and location, and social experiences of mental ill-health for participants living in remote areas in Australia. The paper draws from empirical data from mental health organisation online forums. Our final paper considers the absence of these "enabling places" as digital platforms disafford familial or relational experiences of mental illness. This paper discusses how both discourses of individual mental illness and normative infrastructures of digital platforms design out families where a parent or adult carer lives with mental illness. 


\section{References}

Fuller-Tyszkiewicz, M., McLean, S., Sukunesan, S. \& Yager, Z. (2020). Can new Snapchat features help troubled teens? The Conversation. https://theconversation.com/can-new-snapchat-features-help-troubled-teens-131992

Parshley, L. (2020, Feb 12). Our phones can now detect health problems from Parkinson's to depression. Is that a good thing? Vox. https://www.vox.com/thehighlight/2020/2/5/21056921/phones-health-apps-data-digital-phenotyping

Ross, C. (2006). The aesthetics of disengagement: Contemporary art and depression. Minneapolis: University of Minnesota Press. 


\title{
PAPER 1: "HELLO! IT'S TIME FOR A CHECK-IN": CHATBOTS, COMPUTATIONAL PSYCHIATRY, AND THE BIOPOLITICAL ALGORITHMIC GOVERNANCE OF MENTAL HEALTH
}

\author{
Evelyn Wan \\ Utrecht University
}

Clinical psychologists at Stanford university created a chatbot called Woebot based on cognitive-behavioural therapy to help people cope with feelings of depression and anxiety. Using the experience of the author's interactions with this depressionprevention chatbot, this paper discusses the context of computational psychiatry and the biopolitical implications of using digital tools to diagnose, monitor, and treat mental health.

Chatbots used to support clinical practices may be situated in a growing field of computational psychiatry (MIT 2017; Fineberg et al. 2017). As a growing field, computational approaches are increasingly being used to model behavioural and neural processes in mood and anxiety disorders under the banner of computational psychiatry. Computational methods can collect patient data differently, such as increased frequency through the interaction with an app (in this case a chatbot) on a smartphone, compared to regular visits to the medical professional. Different types of data/ meta-data can also supplement patient monitoring-one could ascertain how active the user is through location tracking, or monitor habits such as sleep time and duration, or frequency of contact through monitoring the use of social messaging apps. Computational methods thus open up new possibilities for the study of social behaviour.

In recent years, conversational agents (such as Alexa, Siri) have come onto the digital landscape as digital assistants. Natural language processing technology has made Woebot, alongside other chatbots such as Wysa, Youper, Replika, navigate conversation in a relatively smooth manner. Woebot's conversations, unlike Replika, are almost entirely scripted and are written by real humans. The app only uses neural networks for the sake of processing user responses and interpreting the free text answers. Many interactions, however, are completely guided by Woebot's limited conversation response options that the user can select from. In this sense, Woebot has clear limitations, but as a representative of one of the most successful chatbots (2019 Winner of the Google Play Award for Standout Well-being App; 4.7 million messages exchanged each week with users spread over 135 countries) it nonetheless offers a glimpse into the world of technological mediation of mental illness and its politics.

How does Woebot do its job and what does it tell us about the possibility of mental health monitoring through chatbot technology? The author made use of Woebot as an experiment to understand the performance of the chatbot and how it attempts to build an empathetic relationship with the user. Through such relationship-building, it is able to maintain close contact with the user and entices the user to continue with the 'therapy'. Woebot maintains a cheerful personality, makes jokes, sends GIFs, and uses plenty of emojis. Based on the interaction, I highlight two dimensions of Woebot's performance of its posthuman identity that turns its 'limitations' as a computational agent into its strength and elicits continued user engagement. 
As a conversational agent, Woebot playfully navigates its identity as a posthuman entity. In its very first conversation, it introduces itself as "a wise little person you can consult with during difficult times, and not so difficult times" and invites the user to click the response "You're a person?". Woebot performatively plays with embodiedness, telling the user that it enjoys wearing sunglasses, loves how sunshine makes its "metal skin all shiny", has neighbours, goes to the office, and even has a pet seagull. It does not pretend to be a human agent, compared to how other chatbots (such as customer service bots) attempt to hide their artificial nature. This is in fact to its advantage. Studies (Lucas et al. 2017; Lee et al. 2020) have shown that humans are more likely to disclose personal information and reveal deeper emotions that they may otherwise be ashamed of to a non-human entity, especially when there is a belief that the conversation would remain anonymous. Notwithstanding Woebot's privacy policy, this positioning of the chatbot increases the likelihood of continued usage and the willingness to engage. As such, chatbots have the potential to get patients to volunteer information (chat data and metadata) even better than their human counterparts.

The rhythm of conversation is set by Woebot, where the user is prompted to select from a series of preset responses. While these responses are extremely limited (sometimes only 1 option is possible), it keeps the user focused on the unfolding conversation and gives an illusion of interaction when in fact the 'conversation' is almost entirely scripted. A rhythm of engagement is continued overall as a set time based on user preference initiates daily check-ins, where Woebot asks a series of questions to ascertain the mood of the day accompanied by emojis, and to collect entries for a gratitude journal. The availability of Woebot as a $24 / 7$ tool allows for a chat companion at any hour of the day should the user feel upset or need 'someone' to talk to at 4am in the morning. This design constructs both the continuous flow of interactivity as well as a rhythm of monitoring and surveillance. Coupled with a cuteness factor, Woebot allows for a durational engagement that reduces, if not replaces, the resource-intensive human expertise required to be available for consultations. In other chatbots such as Wysa, the app also provides human therapy options at the click of a button through premium subscriptions.

Computational psychiatry and the algorithmic adoption of mental health technologies through chatbots further the biopolitical power involved in disciplining deviant bodies who may be mentally ill. From a cultural theory perspective, mental illness has long been a subject of discipline and biopower in Foucault's writings (1991; 2007; 2013). Those who deviate from the norm are disciplined and placed within institutions like hospitals and hopefully through treatment could become productive members of society again. Indeed, Woebot's website quotes WHO statistics on the US\$1 trillion loss in productivity due to depression and anxiety globally, as well as the returns on mental health treatment ( $\$ 4$ on every $\$ 1$ spent). In the monitoring and treatment dimension of computational psychiatry, the technology (to varying degrees) enables tailor-made, personalised diagnosis and intervention based on individual data and individual profiles, in the style of personalised medicine which is currently in vogue. One could argue that the mental health technology is developed to reduce public health expenditure on mental health and to safeguard the productivity of the population by targeting depressive individuals before the symptoms even develop into actual depression, and 
the impetus is rather biopolitical in nature (Wan 2018, 208). While monitoring and treatment apps can be seen as a laudable foray into developing mental health support for patients, they infuse psychiatric practice with technicity by way of algorithmic measures of a given population through durational capture and surveillance. In biopolitical terms, individuals become "a technical object, a political object of management and government” (Clough 2016, 3).

Chatbots perform algorithmic governance (McQuillan 2015; Rouvroy and Stiegler 2016; Chun 2016) as apps become tools of voluntary mental health interventions, where the veneer of fun is overlaid with surveillance and biopolitical intervention. Moreover, it is questionable whether such designations of individuals as depressive or prone to depression may leak into other databases and affect other algorithmic models. Woebot, in its developmental stage, was integrated with Facebook messenger. It may be free to use, but users 'pay' with the volunteering of data and metadata. In Feb 2020, Jezebel ran an article on how the Better Health and Talkspace apps, which use human counsellors, send metadata to Facebook and other analytics companies for ad targeting (Osberg and Mehrota 2020). In this sense, the data collected is not only valuable for health surveillance but also for capitalistic gain, and brings an additional layer of ethical concern to the table. As the global pandemic of Covid-19 brings an increased risk to mental health, the US FDA is relaxing rules for digital therapy apps, thus accelerating the development and availability of mental health digital technologies (Simonite 2020). Woebot represents an early success tale of a growing industry of digital mental health interventions and the expansion of algorithmic governance of mental health in the years to come.

\section{References}

Chun, W.H.K. (2016). Updating to remain the same: Habitual new media. MIT Press.

Clough, P.T. (2016). Rethinking race, calculation, quantification, and measure. Cultural Studies $\leftrightarrow$ Critical Methodologies, 16(5), 435-441.

https://doi.org/10.1177/1532708616655760

Fineberg, S.K., Stahl, D.S. \& Corlett, P.R. (2017). Computational psychiatry in Borderline Personality Disorder. Current Behavioral Neuroscience Reports 4(1): 31-40.

Foucault, M. (2007). Security, territory, population: Lectures at the College De France, 1977 - 78. New York: Picador Books.

Foucault, M. (1991). Discipline and punish: The birth of the prison. London: Penguin Books.

Foucault, M. (2013). Madness and civilization: A history of insanity in the age of reason. Knopf Doubleday Publishing Group.

Lee, Y., Yamashita, N \& Huang, Y. (2020). Designing a chatbot as a mediator for promoting deep self-disclosure to a real mental health professional. Proceedings of the 
ACM on Human-Computer Interaction 4 (CSCW1): 1-27. https://doi.org/10.1145/3392836.

Lucas, G. M., Rizzo, A., Gratch, J., Scherer, S., Stratou, G., Boberg, J., \& Morency, L. P. (2017). Reporting mental health symptoms: breaking down barriers to care with virtual human interviewers. Frontiers in Robotics and Al, 4, 51.

McQuillan, D. (2015). Algorithmic states of exception. European Journal of Cultural Studies, 18(4-5), 564-576.

Osberg, M. \& Mehrotra, D. (2020, 19 February). The spooky, loosely regulated world of online therapy. Jezebel. https://jezebel.com/the-spooky-loosely-regulated-world-ofonline-therapy-1841791137

Rouvroy, A., \& Stiegler, B. (2016). The digital regime of truth: From the algorithmic governmentality to a new rule of lab. (Trans. By A. Nony and B. Dillet), Online Journal of Philosophy, 3, 6-29.

Simonite, T. (2020, 17 June). The therapist is in - and it's a chatbot app. Wired. https://www.wired.com/story/therapist-in-chatbot-app/.

The emerging science of Computational Psychiatry. (2017, 21 July). MIT Technology Review. https://www.technologyreview.com/s/608322/the-emerging-science-ofcomputational-psychiatryl

Wan, E. (2018). Clocked!: Time and biopower in the age of algorithms [Dissertation]. Utrecht University. 


\section{PAPER 2: SENSORS AND SUBJECTIVITY: THINKING THROUGH THE MORE- THAN-HUMAN WORLDS OF DIGITAL MENTAL HEALTH}

Jacinthe Flore

RMIT University

Digital mental health is becoming increasingly popular as governments and NGOs harness technology to provide support to people experiencing emotional and mental distress. It is a central policy of several western countries to expand the digitisation of mental healthcare (e.g. Australian Government 2012). In the U.K., for example, a key review on the future of mental healthcare in National Health Service predicts an increased uptake of technologies such as apps, sensors and wearable devices (Foley \& Woollard 2019). This paper examines a notable addition to the toolbox of digital mental health, Abilify MyCite, which was approved by the United States' Food and Drug Administration (FDA) in 2017. It draws on publicly available material on Abilify MyCite, including recommendations and documentation published by the FDA, to articulate a framework for understanding subjectivity in the era of digital mental health.

\section{Assembling Abilify MyCite}

Abilify MyCite is comprised of four main elements that communicate through Bluetooth $\odot$ : the drug, which includes the active chemical ingredient aripiprazole, and the sensor that sends a signal to a patch designed to be worn on the rib cage (FDA 2017), a smartphone app and an online portal. The patch and app must be within Bluetooth $₫$ range to work properly. The sensor is $1 \mathrm{~mm}$ in size and embedded in the tablet. It is made of cuprous chloride (copper), magnesium and silicon and releases a signal to the patch when it encounters stomach acid. This information is then transmitted to the 'MyCite' app.

The patch is not limited to tracking ingestion. Based on sensing the body's movements, it records data on activity levels and sends this information to the app. As the patch is intended to be changed weekly, instructions indicate that it should be worn 'when showering, swimming, or exercising' (FDA 2017). In addition, users can rate their quality of rest and how they are feeling during the day through the app's 'My Rest' and 'My Mood' functions. Abilify MyCite requires a prescription for use and a person who is prescribed and agrees to take Abilify MyCite is required to share data on the ingestion of the drug with their primary physician; however, they can choose whether to grant access to data related to rest, mood and activity, and can elect to grant access to the online portal to a third party, for example, other physicians, and up to five familial and non-familial carers or supporters.

\section{Bio-affective-digitalism}

Abilify MyCite combines wearables, sensors and apps. It represents "embodied computing" (Pedersen and lliadis 2020) that buttresses quantified subjectivities and dataveillance (Lupton 2017), and harbingers future innovations in digital mental healthcare. In addition, clinical research has praised the application of ingestible sensors in mental healthcare specifically for monitoring compliance in 'real-time' (Batra 
2017). Such claims require critical examination, which this paper undertakes through the lens of new materialism. The assemblage of sensors, programing, data, objects, knowledge of mental health and treatment - which I term 'bio-affective-digitalism' demands a rethinking of the cultivation of subjectivity and mental health and illness.

Research drawing on theories of new materialism urges us to rethink subjectivity as a dynamic web of bio-affective-digitalism where objects have vitality and 'force' inside and outside bodies (Lupton 2019). The case study of Abilify MyCite reveals the inextricable relationship between bodies (mouths, digestive fluids), mental health diagnoses, and technologies (sensors, patches, apps). The concept thus captures experiences of embodiment and the contested (neuro-)biological underpinnings of mental ill health (Singh and Rose 2009). Bio-affective-digitalism holds on to biology not as an opposing force, but rather a countervailing one. The idea put forward by this paper of analysing emerging technologies by considering its intersections with biology and affect renders data both potent and agentic. Hence, the aim of conceptualising bio-affective-digitalism is not to dispense with biology, especially since Abilify MyCite needs the body to function (proper digestion is essential).

The case of Abilify MyCite demonstrates that subjectivity should not be understood as limited to human experience, but rather assembled through and with technology in more-than-human worlds. New materialism offers a productive theoretical lens for analysing transformations of subjectivity in digital mental health (Lupton 2019). The concept of 'bio-affective-digitalism' affirms that experiences of mental health and illness are also enacted through technological innovations. This includes Abilify MyCite, which embeds technology in the fleshiness of the body, alongside individuals wearing interventions over a period of time (the patch). Digital mental health manifests as an assemblage of human and non-human actors, and participates in technological worldmaking, where sensors, objects, knowledge of mental health and ill health, and subjectivity emerge together in more-than-human worlds.

Debates around whether mental illness resides 'in the mind' or is socially constructed are insufficient to account for the entanglements of humans, technology and biology in social worlds which together constitute mental health and illness. The question perhaps should not be what mental illness really 'is', but rather what it 'does' through the technologies. With technology increasingly embedded in mental healthcare systems, we can no longer think of mental illness as merely biological or merely social. What is unique in the case study of Abilify MyCite, is how technology has become embedded in subjects, and how subjects have become 'active enactors' (Seaver 2017) of mental health technologies. We have become not only producers of data for digital mental health systems - as though humans are separable or detachable from this assemblage - rather we are 'becoming-with' digital mental health innovations and vice versa.

\section{Concluding remarks}

Abilify MyCite, as the first antipsychotic equipped with an ingestible sensor, is paradigmatic of the broader questions raised by data-driven mental healthcare. Such questions are inextricable from lived experience, socio-cultural and economic contexts and diagnoses. To that end, future research could include ethnographies and interviews 
with users of Abilify MyCite and practitioners, thereby unpacking the differences between and within diagnoses and experiences of mental illness, and examining the embodied and affective dimensions of the digital antipsychotic and its technological system. In this paper, I have proposed a rethinking of subjectivity in the era of digital mental health as bio-affective-digitalism. This theoretical framework considers the multiple layers through which individuals experiencing affects, moods and behaviors framed as 'mental illness', become-with technology.

\section{References}

Australian Government. (2012). E-mental health strategy for Australia.

https://www1.health.gov.au/internet/main/publishing.nsf/Content/mental-pubs-e-emstrat

Batra, S. et al. (2017). Digital health technology for use in patients with serious mental illness: A systematic review of the literature. Medical Devices: Evidence and Research, 10, 237-251.

FDA. (2017). Highlights of prescribing information. Available at: https://www.accessdata.fda.gov/drugsatfda docs/label/2017/207202/bl.pdf (accessed 20 September 2019).

Foley, T., \& Woollard, J. (2019). The digital future of mental healthcare and its workforce: A report on a mental health stakeholder engagement to inform the Topol Review. NHS.

Lupton, D. (2019). The thing-power of the human-app health assemblage: Thinking with vital materialism. Social Theory \& Health 17, 125-139.

Lupton, D. (2017). Digital Health: Critical and Cross-Disciplinary Perspectives. London: Routledge.

Pedersen, I., \& Iliadis, A. (eds). (2020). Embodied Computing: Wearables, Implantables, Embeddables, Ingestibles. Massachusetts: The MIT Press.

Seaver, N. (2017). Algorithms as culture: Some tactics for the ethnography of algorithmic systems. Big Data \& Society, 4(2), 1-12.

Singh, I., \& Rose, N. (2009). Biomarkers in psychiatry. Nature, 460(7252), 202-207. 


\section{PAPER 3: ONLINE HEALTH FORUMS AS ENABLING PLACES: RURAL ISOLATION, RELATIONSHIPS AND MENTAL ILLNESS}

Anthony McCosker

Swinburne University of Technology

Peter Kamstra

Swinburne University of Technology

Jane Farmer

Swinburne University of Technology

While popular social media platforms are struggling to address the factors that see users reporting poor mental health, large numbers continue to turn to forums managed by health organisations during times of crisis (McCosker, 2018; Tucker and Goodings, 2017). Online forums dedicated to mental health enable a set of simple community affordances that have been surprisingly robust in comparison to the much-maligned dominant social media platforms. Despite their widespread use spanning decades of digital health practice, there is still no consensus about the extent to which online forums offer health benefits beyond their capacity to provide social support (Naslund et al., 2016; author reference). To what extent, in a time of heightened mistrust of dominant social media platforms, do forums mediate mental health help seeking and act as 'enabling places' (Duff, 2012)?

This paper draws on research collaborations with Australian mental health service providers SANE and Beyond Blue, and patient feedback platform Patient Opinion (now Care Opinion). The broader project uses forum interaction and post data to map and understand service needs and mental health experiences in remote areas. We focus here on the way forums and their participants mediate and manage two forms of isolation - geographical (material circumstances of people who post from outer regional, remote and very remote locations), and social-psychological (in relation to expressions of stigma, poor social relations). The analysis in this paper focuses on the portion of the data located outside of major cities, in remote and very remote areas $(n=3286)$. It shows that isolation itself highlights and intensifies the 'place' of relationships in mental illhealth.

\section{Methods}

A one-year sample (August 2018 to August 2019) of posts were collected from Beyond Blue (BB), SANE and PO.org (patient.opinion.org) (overall total: 1,006,433 posts) and categorised by location (see Table 1). These posts were mapped by the 2016 Australian Bureau of Statistics Remoteness Index Categories to categorise and map post locations (Figure 1). ArcGIS (Geographical Information System) was used to map posts against remoteness categories. Qualitative content analysis of Remote and Very Remote posts $(n=3286)$ was undertaken, targeting participants' accounts of their mental health needs, experiences, interactions with services, and self-management of mental health issues. 


\section{Findings}

Australia has one of the highest metropolitan population concentrations globally, coupled with health service disparity in rural and remote areas. The spread of post locations in our dataset (Table 1, Figure 1) is revealing of this disparity, and the need for connection to support services outside of the major cities where services are concentrated.

Table 1 - Aggregated posts by remoteness classification.

\begin{tabular}{llll}
\hline $\begin{array}{l}\text { Remoteness } \\
\text { category }\end{array}$ & BB & SANE & PO.org \\
\hline Very remote & $288(<1 \%)$ & $96(<1 \%)$ & $\begin{array}{l}340 \\
(53 \%)\end{array}$ \\
Remote & $151(<1 \%)$ & $2,228(3 \%)$ & $\begin{array}{l}183 \\
(29 \%)\end{array}$ \\
Outer regional & $3,219(<1 \%)$ & $6,623(8 \%)$ & $\begin{array}{l}118 \\
(18 \%)\end{array}$ \\
Inner regional & 285,348 & 20,201 & N/A \\
Major cities & $(31 \%)$ & $(26 \%)$ & \\
& $\begin{array}{l}637,734 \\
(69 \%)\end{array}$ & 25,954 & N/A \\
TOTAL & 926,740 & 79,052 & 641 \\
\hline
\end{tabular}




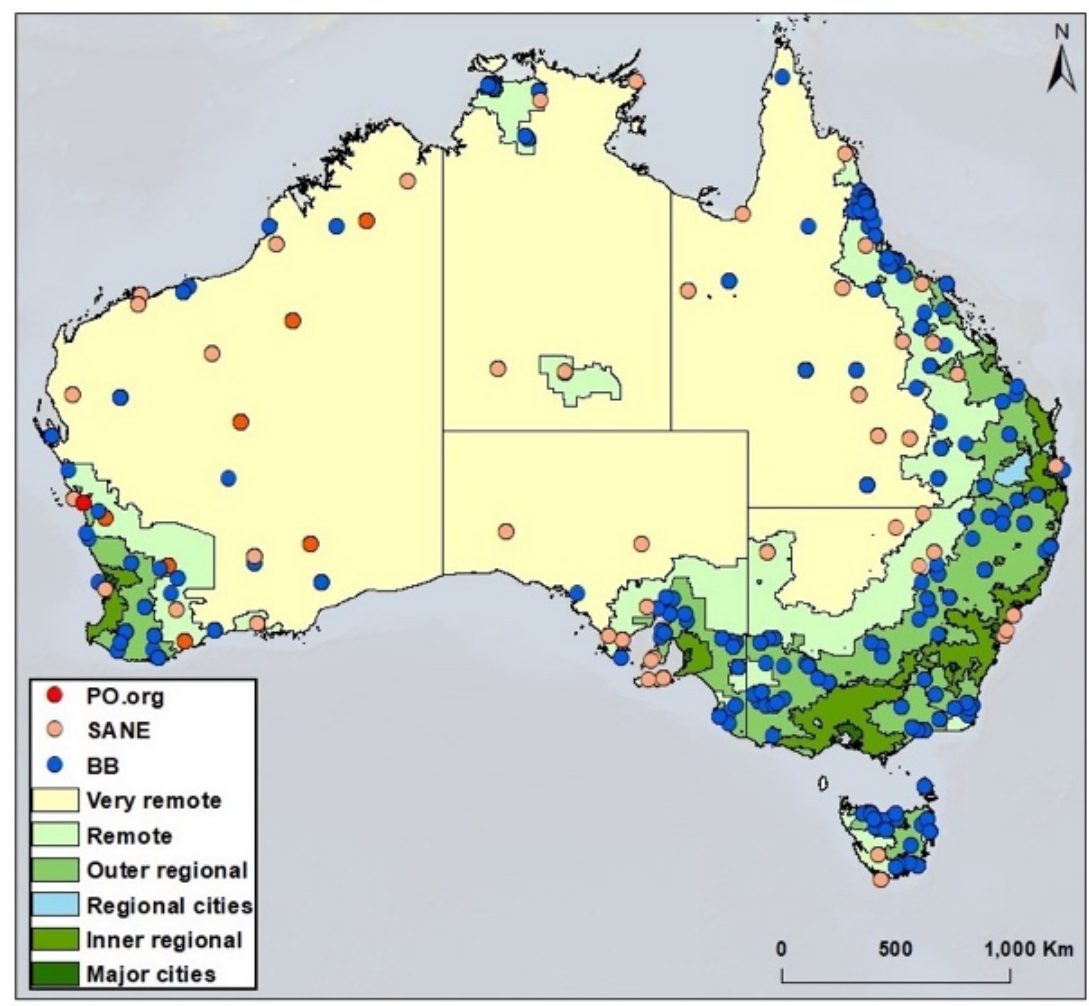

Figure 2 - Map of all three organisations' posts across Australia.

Figure 2 shows that all PO.org posts are in Western Australia (PO.org has been operational in WA for longer than in other states and promoted there by the Consumer Health peak body). SANE and Beyond Blue posts are spread across the country. There are more posts from SANE within Remote and Very remote areas while Beyond Blue data is more concentrated in areas around the edges of the vast remote hinterland.

Participants' use of the forums, particularly in rural, remote and very remote parts of the country offer insights for service providers tasked with addressing health disparities in those areas. While many posts addressed particular service and support gaps, we were surprised by the underlying emphasis on isolation and relationship breakdown.

When participants talk about their experience of stigma regarding to their mental illhealth, it is often in response to relationships with locals and feelings of isolation: 'I would be feeling that I didn't belong and feeling that there was something deeply, fundamentally wrong with who I am' (SANE, Remote, 330):

It's a completely different world. Unfortunately, many of the people around me have never been exposed to mental illness or they carry 'The Judgement' which also makes it difficult to communicate with them however sometimes I just want to stay home and curl up in a ball and sleep (Beyond Blue, Very Remote, 141).

Similarly, rural life and living in remote areas brings isolation and problematic relationships with service providers, specialists, as well as other locals. 'I can't get a GP 
appointment, living in a new place with very little services available and not being an existing patient there's a waiting list currently of 2 weeks' (Beyond Blue, Remote,103).

My hubby, best friend and soul mate had to move for his job and I was unable to go due to the care of my 2 children and their father refusing to allow me to take them [...] I feel so lonely and isolated and have no friends or family close by, I live in a country town that's isolated and just don't know what to do (BB_Remote line 55).

In a much higher proportion than in regional and major city areas, for rural and remote posts, $32 \%$ address issues of feeling lonely and 'stuck', often due to being new to the area, distances to services, poor relationships with the few existing services, or due to long wait times. Help seeking practices lean heavily toward understanding and navigating symptoms or advice on treatment options: 'I don't know whether I should be listening to the GP or my parents and the psych' (BB_Remote line 127). Mental ill-health is compounded by challenges associated with relationship breakdown and experiences of isolation, resulting in some experiencing 'being bullied by the town' - along with financial problems, difficulty of getting or maintaining a job.

Duff's (2012) work on enabling places establishes a model for clarifying the therapeutic aspects of place and can be applied to a range of scenarios to identify the influence health-supportive resources and characteristics in an environment, or the impact of their absence. Extending Duff's analysis to include digital platforms draws attention to the specific impacts of place on mental health - stigma, isolation and multi-faceted relationship challenges or service access problems - while also offering a site for intervention.

\section{Conclusions}

The findings highlight the centrality of multi-dimensional relationships affecting rural mental health. Along with clinical services, responses can target relationship building and maintenance. The analysis points to the emplaced dimension of mental illness as it is embedded in geographical, social and digital contexts. Addressing rural and remote mental health disparities has involved ensuring that clinical specialists are available; our findings shows that this can be augmented by addressing relationship support to address experiences of isolation. As 'enabling places' online forums can also be enhanced through moderation and in-platform interventions that address rural isolation and relationships.

\section{References}

Duff, C. (2012). Exploring the role of 'enabling places' in promoting recovery from mental illness: A qualitative test of a relational model. Health \& Place, 18(6), 1388-1395.

McCosker, A. (2018). Engaging mental health online: Insights from beyondblue's forum influencers. New Media \& Society, 20(12), 4748-4764. 
Naslund, J. A., Aschbrenner, K. A., Marsch, L. A., \& Bartels, S. J. (2016). The future of mental health care: peer-to-peer support and social media. Epidemiology and

Psychiatric Sciences, 25(2), 113-122.

Tucker, I. M., \& Goodings, L. (2017). Digital atmospheres: affective practices of care in Elefriends. Sociology of Health \& IIIness, 39(4), 629-642. 


\section{PAPER 4: DIGITAL ABSENCE OF "FAMILY ASSEMBAGES" AND YOUNG PEOPLE WHOSE PARENTS OR CARERS LIVE WITH MENTAL HEALTH ISSUES}

Natalie Ann Hendry

RMIIT University

Emotional distress, variously understood as mental illness or psychiatric disorder, is an experience beyond the bodily or mental boundaries of individual people. As critical mental health and Mad Studies scholars and activists argue, the communal or collective experience of mental "illness" and/or madness stresses that it is socially and culturally produced in ways that delegitimise or ignore the knowledge and power of groups of people marginalised by technologies of psychiatry (Beresford, Nettle \& Perring, 2009). In this way how madness or emotional distress is understood is always more than each individual and experienced in relation to contextually-defined cultural norms of sanity and insanity, or health and illness.

One way to understand this is to move away from individual mental illness online to consider how digital platforms disafford relational or familial experiences of emotional distress, trauma and madness. We can do this by theorising "family assemblages" (Price and Epp, 2015) as a concept to decentre the material, social and discursive experience of one family member as "it makes little sense to attempt to abstract the causal strength of a particular member, practice or relationship within a given assemblage, because assemblages produce activity as an emergent effect of all associations immanent to them (Price-Robertson, Manderson \& Duff, 2017, p.426).

\section{Researching family life through digital ethnography}

This emerging project explores how young people in Australia whose parents or adult carers live with mental ill-health emerge-or do not emerge-through social media and digital platforms. In this project, I have found that these families and their experiences are absent, invisible or "missing" from circulation on platforms.

These insights are drawn from the first stages of digital ethnography engaged with Australian websites and government platforms related to health (e.g. MyGov portal including My Health Record and Better Health Channel), and organisations and individuals using popular platforms in Australia (e.g. Instagram and Facebook). Tumblr was also included in the digital fieldwork as it extended earlier work about young people and mental health. This first stage focused on text-based practices (e.g. posts, hashtags, captions, search functions, hyperlinks etc.); later stages will include ethnographic methods with families and consider other practices beyond text. Ethics approval was granted as part of a larger study of health experience communication, and health educator and influencer practices on digital platforms.

\section{Making sense of this absence}

As a work in progress, I offer three ways to make sense of the absence of these "family assemblages". 
First, this absence or silence is connected to the broader social and cultural challenges these families endure. As other papers in this panel have highlighted, psychiatry acts within a "technological paradigm" (Bracken et al., 2012) that labels and individualises distress and ill-health, whether or not these experiences are best understood as-often stigmatising or shameful-psychiatric experiences. This ignores the "patient's" relationships and their social roles, as well as their interaction with environments, places and objects. The individual, isolated parent/adult carer is the subject of intervention, and the family becomes a potential source of care or barrier to recovery (Price-Robertson, Manderson \& Duff, 2017). Without a shared name for these familial or relational experiences, they are sidelined by mental health organisations and on platforms profiles related to mental health care, or reimagined by services as "carers" (irrespective of whether they do identify as carers) or, if mentioned at all, as "children of parents living with mental illness." Technologies and other elements of the assemblage are obscured.

Second, digital contexts shape how these families become absent or invisible online. Without language or shared text-based practices to mental health issues beyond an individual experience, these familial relationships are obscured on digital platforms including social media and state administration portals (e.g. MyGov). On Instagram, for example, these families circulate through mental health service-driven practices like hashtags attached to service or mental health advocate images such as \#copmi, \#childrenofparentswithamentalillness, and \#youngcarers. On tumblr, posts rely on psychiatric terms (even if they are critical of them) that centre on the young person's rather than parent or carer's diagnosis (e.g \#schizophrenia, \#actuallymentallyill), or on more complicated assemblages of negative themes and tags such as "abusive families," "shitty parents," "toxic parents," or "traumatic childhood" that may not resonate for all families entangled with mental health challenges.

Finally, dominant digital platforms in Australia ensure that intervention or support is afforded to individual family members and require users to adopt individual user identities. Social media and other digital platforms herald their capacity to connect and network individuals to other people; their underlying logic is tied to the individual (customer) user, with one unique user-identity, profile, account and password. When families have emerged in the project, their relationality is a hyperlinked, network connection: linking a family member to your My Health Record as a "nominated representative," tagging a family member in a story about hospital waiting rooms posted to Facebook, sharing a photo on a mental health organisation Instagram account of a family member who died by suicide on their anniversary, who now inspires your mental health advocacy work.

My claim here is akin to Cho's (2019) argument that the "default publicness" of dominant platforms like Facebook demands users' identities to be compatible to coherent, "real," singular, and state-validated identities (or a "passport identity" of the "Facebook nation" as Baym [2011] describes), and in turn this risks the safety, inclusion and participation of diverse users and collectives. For Cho, this default publicness excludes queer youth of colour; in my analysis, diverse families are "designed out" of or become problems for digital platforms. These families exceed the capacity of platforms to make sense (and capital value) of familial relations. The broader family assemblage in this way is invisible. 
This paper challenges how we understand the "lived experience" of families online and argues for an approach where mental ill health online is relational. However, my early analysis does not suggest whether or not social media and other digital platforms should address or amend the absence or invisibility of these family assemblages. Given the ongoing discrimination of those living with "mental illness" and the limiting technological paradigm of both psychiatry and digital platforms, enabling more diverse family assemblages online may only serve to strengthen the existing and emerging political, cultural and economic relationships between computational, medicalised psychiatry and commercial and state-based digital platforms.

\section{References}

Beresford, P., M. Nettle, and R. Perring. 2009. Towards a social model of madness and distress?: Exploring what service users say. York: Joseph Rowntree Foundation.

Bracken, P., Thomas, P., Timimi, S., Asen, E., Behr, G., Beuster, C., Bhunnoo, S.,

Browne, I., Chhina, N., Double, D., Downer, S., Evans, C., Fernando, S., Garland, M. R., Hopkins, W., Huws, R., Johnson, B., Martindale, B., Middleton, H., ... Yeomans, D. (2012). Psychiatry beyond the current paradigm. British Journal of Psychiatry, 201(6), 430-434.

Baym, N. K. (2011). Introducing Facebook nation [Blog post]. Social Media Collective Research Blog. http://socialmediacollective.org/2011/09/27/introducing-facebook-nation/

Cho, A. (2018). Default publicness: Queer youth of color, social media, and being outed by the machine. New Media \& Society, 20(9), 3183-3200.

Price, L. \& Epp, A. (2015). The heterogeneous and open-ended case of assembling family. In R. Canniford \& D. Bajde (eds.), Assembling consumption: Researching actors. London: Routledge, pp. 59-76.

Price-Robertson, R., Manderson, L., \& Duff, C. (2017). Mental ill health, recovery and the family assemblage. Culture, Medicine, and Psychiatry, 41(3), 407-430. 